\title{
Biochemical Properties of Staphylococci Sensitive and Resistant to Sulphonamides
}

\author{
By P. J. WHITE* and the late D. D. WOODS \\ Microbiology Unit, Department of Biochemistry, University of Oxford
}

(Received 26 February 1965)

\section{SUMMARY}

Four staphylococcal substrains resistant to sulphonamides were developed from sensitive parent strains by subcultivation in increasing concentrations of sulphathiazole. As compared with the parent strains, the growth of the resistant strains was 20-200-fold less sensitive to sulphathiazole in a semi-defined medium based on acid hydrolyzed casein than were the parent strains. Inhibition of growth by sulphathiazole was overcome competitively by $p$-aminobenzoic acid. The inhibition indices of the sulphathiazole-sensitive strains were about 10, and 100-1000 for the resistant substrains; the change in index was about proportional to the degree of resistance. The sulphathiazole-resistant strains were cross-resistant to other sulphonamides but were not resistant to $p$-nitrobenzoic acid. Not one of the sensitive or resistant strains was inhibited by aminopterin.

No change in the inhibitory effect of sulphathiazole occurred during growth of cultures in its presence, though the drug was partly converted to a second substance (of unknown structure). Resistant and sensitive pairs of strains formed similar amounts of unknown compound, so that it is unlikely that its formation has to do with resistance. Concentrated suspensions of organisms of all strains took up similar amounts of $\left[{ }^{35} \mathrm{~S}\right]$-sulphathiazole when incubated in the growth medium. The attachment of the drug to the organisms was weak, but the uptake was not altered by the presence of $p$-aminobenzoic acid. The rates of aerobic growth and the nutritional requirements for anaerobic growth of sensitive and resistant strains were generally similar. The nutritional requirements for vitamins and amino acids varied among the sensitive strains, but there were only slight differences between resistant and sensitive pairs of strains.

\section{INTRODUCTION}

The syntheses of $p$-aminobenzoic acid and of folic acid (Lactobacillus casei factor) have been studied in three strains of staphylococci sensitive to sulphanomide-drugs and in five resistant strains (White \& Woods, 1965). In only one of the resistant strains (Staphylococcus aureus $\mathrm{R} 122$ ) was synthesis of $p$-aminobenzoic acid strikingly higher than in the sensitive strains, and only in this and one other resistant strain (Staphylococcus lactis $2102 \mathrm{R}$ ) was synthesis of folic acid increased above the value of the sensitive strains. All the resistant strains were able to synthesize folic acid from $p$-aminobenzoate, glucose and glutamate in the presence of higher concentrations of sulphathiazole than were the sensitive strains. Several biochemical

* Present address : Twyford Laboratories, Twyford Abbey Road, London, N.W, 10. 
mechanisms might contribute in the resistant strains to the decreased sensitivity to sulphathiazole of folic acid synthesis and of growth(Davis \& Maas, 1952; Davis, 1957). To investigate some of these possibilities, the uptake and metabolism of sulphathiazole were examined. Other properties of sensitive and resistant strains were also compared to try to reveal further biochemical differences accompanying resistance.

\section{METHODS}

Organisms. The organisms and methods of cultivation were those used by White \& Woods (1965). Staphylococcus lactis $2102 \mathrm{R}, 2102 \mathrm{R} 2$, S. aureus JHMR and HR 2 were sulphonamide-resistant substrains of $S$. lactis $2102, S$. aureus JHM and $\mathrm{H}$, respectively; $S$. aureus $\mathrm{R} 122$ was a strain which was resistant to sulphonamides when isolated.

Media. These were prepared at double strength and brought to the desired volume with water and other experimental additions before autoclaving for $7 \mathrm{~min}$. at $115^{\circ}$. Medium B was the semi-defined medium based on acid-hydrolyzed casein, which was described by White \& Woods (1965). For anaerobic growth of staphylococci, medium $\mathrm{B}$ was supplemented with (mg./l.): $\mathrm{NaNO}_{3}, 170$; uracil, 5 ; sodium pyruvate, $220 ; \mathrm{NaHCO}_{3}, 1700$. The sodium bicarbonate and pyruvate, sterilized by Seitzfiltration, were added to the autoclaved medium.

For the determination of amino acid requirements, the medium of Gladstone (1937) was used. To allow the amino acid content to be varied, each amino acid was made up in concentrated solution so that the addition of $0.1 \mathrm{ml}$. of each gave the final concentration required in $5 \mathrm{ml}$. of the completed medium.

Aerobic growth conditions. Inoculated medium (10 ml.) was incubated in optically matched $150 \times 150 \times 16 \mathrm{~mm}$. $\perp$-shaped glass tubes which were clamped in a rocking device and shaken at $37^{\circ}$ in a water bath at 35 oscillations/min. with an excursion of $10 \mathrm{~cm}$. (Morris \& Woods, 1959). The inoculum was $0.2 \mathrm{ml}$. of a suspension in water of organisms (about $2 \times 10^{5} / \mathrm{ml}$.) derived from an agar slope.

Semi-aerobic growth conditions. Medium ( $5 \mathrm{ml}$.) inoculated as above with $0 \cdot 1 \mathrm{ml}$. of a similar suspension of organisms, was incubated at $37^{\circ}$ in $150 \times 19 \mathrm{~mm}$. tubes, sloped at about $5^{\circ}$ to the horizontal. This was the usual procedure for growth experiments, which were always set up in duplicate.

Anaerobic growth conditions. The usual conditions for growth experiments were followed, with the tubes incubated upright in a glass McIntosh and Fildes jar, in an atmosphere of $95 \%(\mathrm{v} / \mathrm{v})$ hydrogen $+5 \%(\mathrm{v} / \mathrm{v})$ carbon dioxide. The early stages of growth were observed through the sides of the jar, which was not opened at all until the end of an experiment.

Assessment of growth. Growth was estimated routinely by visual examination at intervals of about $12 \mathrm{hr}$ during incubation. When quantitative results were required the turbidity of cultures was measured in $6 \mathrm{~mm}$. diameter tubes with an EEL photoelectric colorimeter (Evans Electroselenium Co. Ltd, Halstead, Essex) with a neutral density filter; the uninoculated medium was used to give the zero setting. The cross-arms of the 1 -tubes were made to fit the instrument, so that the tubes could be read in the colorimeter without withdrawing samples. Measurements of colorimeter readings in 1 -tubes or in $6 \mathrm{~mm}$. diameter tubes on the same culture agreed well. The relation between colorimeter reading and dry weight of organisms in water was linear for each strain of Staphylococcus, up to a reading of 3.0-3.5; 
a reading of 1.0 was equivalent to $\mathbf{0 . 2} \mathrm{mg}$. dry wt. bacteria/ml. Very roughly, $1 \mathrm{ml}$. of a suspension reading 1.0 in the colorimeter corresponded to $10^{8}$ colonies on peptone agar.

Growth of organisms for experiments with washed suspensions. Smaller quantities of organisms were grown in medium $B(25 \mathrm{ml}$.) in $180 \times 32 \mathrm{~mm}$. tubes from large inocula as described by White \& Woods (1965). Larger quantities were grown on the surface of tryptic digest of casein or peptone water, solidified with $2 \%(w / v)$ agar in Roux bottles, for $20 \mathrm{hr}$ at $37^{\circ}$.

Chemical estimation of sulphathiazole. The method of Bratton \& Marshall (1939) was used to estimate sulphathiazole at concentrations of $10 \mu \mathrm{M}$ or higher. A standard curve was established relating concentration of solute to EEL colorimeter reading with green filter (OGR 1). Samples were usually diluted to give readings from $\mathbf{0 . 5}$ to $\mathbf{3 \cdot 0}$ on the scale of the colorimeter.

Measurement of radioactivity. Solutions containing $\left[{ }^{35} \mathrm{~S}\right]$-sulphathiazole were evaporated to dryness under an infra-red lamp on $15 \mathrm{~mm}$. (internal diameter) planchets $1.5 \mathrm{~mm}$. deep. The planchets were stamped out from aluminium sheet $(0.1 \mathrm{~mm}$. thickness) and were washed in acetone and water. A disk (15 mm. diameter) of Green's lens tissue No. 105 was put into a planchet before the solution was added. The disk caused the solution to dry evenly over the bottom of the planchet so that no correction for sample geometry was necessary. Counts were measured with an Ekco automatic scaler, Type N530.D (Ekco Works, Southendon-Sea, Essex). An end-window Geiger-Müller tube Type EHM2/S (General Electric Co. Ltd, Magnet House, Kingsway, London) was connected to the scaler through a quenching probe unit, Ekco Type N558. There was no detectable effect of self-absorption provided the weight of dried sample was less than about $0.5 \mathrm{mg}$.; when necessary, samples were diluted to give weights on the planchet not greater than this. The relation between counts/min. (c.p.m.) and concentration of $\left.{ }^{35} \mathrm{~S}\right]-$ sulphathiazole was linear up to 3000 c.p.m. Sufficient counts were recorded for each solution to ensure that the probable error of the count was less than $2 \%$ (Francis, Mulligan \& Wormall, 1954). Standard solutions of [ $\left.{ }^{35} \mathrm{~S}\right]$-sulphathiazole were counted daily so that c.p.m. could be converted to $\mathrm{m} \mu$ moles sulphathiazole.

The positions of radioactive substances on chromatograms were determined with an unshielded mica end-window Geiger-Müller tube which was connected to a scaler unit through a probe unit. The end-window of the Geiger tube was covered by a thin polythene disk with a hole $2 \mathrm{~cm}$. square in the centre. Squares of this size were lightly drawn down the whole length of a chromatogram and the radioactivity of each square was measured for 2 min. by applying the counting tube window to the paper.

Chromatography. Descending chromatograms were run on Whatman No. 1 or No. 3 paper at room temperature. The solvents (parts by vol.) were: (i) $n$-butanol 80 + water 20 (ii) $n$-butanol 80 + sp.gr. 0.88 ammonia 3 + water 17, with mixtures (i) and (ii) after mixing the upper organic layer was used; (iii) methanol $35+n$-amyl alcohol $17 \cdot 5$ + benzene 35 + sp.gr. $0 \cdot 88$ ammonia 4 + water $8 \cdot 5$; (iv) methanol $35+n$-amyl alcohol $17 \cdot 5+$ benzene $35+2 \mathrm{~N}$-hydrochloric acid to saturation. Mixtures (iii) and (iv) formed single phases (Ekman, 1948).

To detect diazotizable amines, chromatograms were allowed to dry after development, and the paper was then exposed for $10 \mathrm{~min}$. to nitrous fumes generated from 
sodium nitrite + hydrochloric acid. After a further $10 \mathrm{~min}$. in air the chromatograms were sprayed with a solution of $\mathrm{N}$-(1-naphthyl)-ethylenediamine dihydrochloride (100 mg./100 ml. water).

Measurement of uptake of sulphathiazole. The method was similar in principle to that described by Mitchell (1953) for measurement of the permeability of staphylococci to phosphate. Organisms were grown in Roux bottles, harvested, washed and suspended in water. The dry wt. of the suspension was determined, a measured volume taken and the organisms centrifuged down, then resuspended to a measured volume to give a concentration equiv. to about $100 \mathrm{mg}$. dry wt. bacteria/ml. in the solution (at double strength) used for investigation of permeability. This suspension ( $1 \mathrm{ml}$.) was pipetted into a $125 \times 16 \mathrm{~mm}$. tube, and sulphathiazole and other test solutions added to final volume of $2 \mathrm{ml}$. The tube was incubated upright at $37^{\circ}$ and then weighed. The organisms were centrifuged and the supernatant liquid (E) was removed as completely as possible with a fine Pasteur pipette into a clean tube. The tube containing bacteria was reweighed after removing the excess solution from the inner wall with filter paper. In each experiment a tube was incubated in which the sulphathiazole was similarly diluted by the constituents of the incubation mixture, but without the organisms. The concentration of sulphathiazole in this solution (F) and in the supernatant liquid $\mathbf{E}$ was estimated by measurement of radioactivity or occasionally by the method of Bratton \& Marshall (1939). The amount of sulphathiazole associated with the organisms at the end of the incubation, $Z$ c.p.m., is given by $Z=A_{F} V_{F}-A_{E} V_{E}-1 V_{P} A_{E}$, where $A_{E}$ and $A_{F}$ are specific activities (c.p.m./ml.) of supernatant liquid $E$ and solution $F$, respectively; $V_{E}$ and $V_{F}$ are the volumes ( $\mathrm{ml}$.) of $\mathbf{E}$ and $\mathbf{F}$ respectively; $V_{P}$ is the volume (ml.) of the centrifuged pad of organisms. The volumes of $\mathbf{F}$ and $\mathrm{E}$ were calculated from the weights and relative density (1.01) of these liquids. The interstitial volume for closely packed spheres was taken to be $25 \%$ of the total volume of the pad of organisms (Conway \& Downey, 1950), which was also calculated from its weight and relative density $(1 \cdot 13)$.

Biochemical tests. Various biochemical tests were performed on the staphylococci, using the methods described in standard works of bacteriology (Mackie \& McCartney, 1931 ; Kolmer \& Boerner, 1945).

Chemicals. These were of Analytical Reagent quality when available. Aminopterin (4-aminopteroylglutamic acid) was a gift from Lederle Laboratories Division of the American Cyanamide Co. (Pearl River, N.Y., U.S.A.; Dr E. L. R. Stokstad). Sulphonamides were obtained from May and Baker Ltd, Dagenham, Essex. Sodium pyruvate was prepared by Mr R. W. Wakelin. Haematin was prepared by Dr June Lascelles by the method described by Lascelles (1956).

Synthesis of $\left[{ }^{35} \mathrm{~S}\right]\left(\right.$ sulphonyl)-sulphathiazole. 1. p-Acetaminobenzene [ $\left.{ }^{35} \mathrm{~S}\right]$-sulphonyl chloride. Acetanilide $\left(10 \mathrm{~m}\right.$-mole) was reacted with $\left.{ }^{35} \mathrm{~S}\right]$-chlorosulphonic acid (30 m-mole, 7.2 $\mathrm{mC}$ ) under conditions described by Gilman (1932). The product was used without further purification for the next step; yield $1 \mathrm{~g}$. (14\% conversion of [ $\left.{ }^{35} \mathrm{~S}\right]$-chlorosulphonic acid).

2. $\mathrm{N}^{4}$-acetyl-[ $\left.{ }^{35} \mathrm{~S}\right]$ (sulphonyl)-s ulphathiazole. $p$-Acetaminobenzene $\left[{ }^{35} \mathrm{~S}\right]$-sulphonyl chloride (4.3 m-mole) was mixed at room temperature with 2-aminothiazole $(10 \mathrm{~m}$-mole) in $13 \mathrm{ml}$. dry ethyl acetate (Fosbinder \& Walter, 1939). After $18 \mathrm{hr}$ at room temperature the ethyl acetate was removed at $80^{\circ}$. Water $(0.25 \mathrm{ml}$.) was 
added and stirred thoroughly. To decompose any remaining $p$-acetaminobenzene sulphonyl chloride, $80 \%(\mathrm{v} / \mathrm{v})$ acetic acid $(0.21 \mathrm{ml}$.) and water $(1.9 \mathrm{ml}$.) were added and the mixture was warmed to $50^{\circ}$ for $30 \mathrm{~min}$. The suspension of $\mathrm{N}^{4}$-acetylsulphathiazole was cooled to room temperature and left for $4 \mathrm{hr}$ before the solid was collected and washed with cold water. Yield $0.9 \mathrm{~g}$. (70\% conversion of $p$-acetaminobenzene sulphonyl chloride).

3. Sodium $\left[{ }^{35} \mathrm{~S}\right]$-(sulphonyl)-sulphathiazole. Sodium hydroxide $(0 \cdot 36$ g.) was dissolved in water in a $125 \times 16 \mathrm{~mm}$. tube; $\mathrm{N}^{4}$-acetyl-[ $\left.{ }^{35} \mathrm{~S}\right]$-(sulphonyl)-sulphathiazole ( 0.9 g.) and 'Norite' active charcoal $(30 \mathrm{mg}$.) were added, and the volume was made up to $3.5 \mathrm{ml}$. The mixture was boiled vigorously for an hour, allowing the volume to fall to $3 \cdot 1 \mathrm{ml}$. The mixture was filtered and the charcoal washed with water $\left(0.15 \mathrm{ml}\right.$.). The filtrate was brought to $80^{\circ}$ and sodium chloride $(0.7 \mathrm{~g}$.) was added. The mixture was cooled to $20^{\circ}$, and the precipitate of sodium [ ${ }^{35} \mathrm{~S}$ ]-sulphathiazole was collected and washed twice with cold saturated sodium chloride solution $(0.3 \mathrm{ml}$.).

4. Purification and isolation of $\left.{ }^{35} \mathrm{~S}\right]$-(sulphonyl)-sulphathiazole. Damp sodium sulphathiazole was dissolved in water and the volume made up to $7 \mathrm{ml}$. 'Norite' charcoal (30 mg.) was added and the mixture was stirred for an hour at room temperature before filtering. The charcoal was washed twice with water $(0 \cdot 3 \mathrm{ml}$.). Concentrated hydrochloric acid was added to the filtrate, until the initial precipitate redissolved. Citric acid (15 mg.) and 'Norite' (15 mg.) were added and the mixture was stirred for an hour. The charcoal was filtered off and washed with water (0.3 ml.). A solution of ammonia was prepared from sp.gr. 0.88 ammonia (6.4 ml.) and water $(12 \mathrm{ml}$.), and was added to the filtrate until it was alkaline to Congo Red, but acid to litmus. The suspension of $\left[{ }^{35} \mathrm{~S}\right]$-(sulphonyl)-sulphathiazole was cooled and filtered. Yield $0.45 \mathrm{~g}$. (58\% conversion of $\mathrm{N}^{4}$-acetyl-[ $\left.{ }^{35} \mathrm{~S}\right]$-(sulphonyl)-sulphathiazole.) Mixed melting point with authentic sulphathiazole ${ }_{198-200}{ }^{\circ}$. The $\left[{ }^{35} \mathrm{~S}\right]$-sulphathiazole resembled authentic sulphathiazole on chromatography with butanol + ammonia and with methanol + benzene $+n$-amyl alcohol + ammonia $\left(R_{F}\right.$ values $0 \cdot 45$ and $0 \cdot 40$ in the two solvents, respectively.) The [ $\left.{ }^{35} \mathrm{~S}\right]$-sulphathiazole (mM) inhibited growth of Staphylococcus aureus JHM in medium B. This inhibition was overcome by $p$-aminobenzoic acid $(0 \cdot 1 \mathrm{~mm})$ after $40 \mathrm{hr}$ incubation. Similar results were obtained with authentic sulphathiazole.

[ $\left.{ }^{35} \mathrm{~S}\right]-$ Chlorosulphonic acid was obtained from the Radiochemical Centre, Amersham, Buckinghamshire. 2-Aminothiazole (specially purified material) was a gift from May and Baker Ltd, Dagenham, Essex.

\section{RESULTS}

\section{Effects of inhibitors}

Sulphonamides. The sensitivities of the various strains of Staphylococcus towards sulphathiazole, sulphanilamide, sulphadiazine and sulphapyridine were determined in medium $B$ (Table 1). The highest concentrations of sulphadiazine and sulphapyridine that could be used were limited by the low solubilities of these substances in water. All the strains were most sensitive to sulphathiazole; sulphadiazine was the next most potent inhibitor and sulphanilamide the least effective. Resistance was not specific to the drug used to develop the resistant strain. The sensitivities 
of the organisms to sulphathiazole were unchanged at the end of $2 \frac{1}{2}$ years, during which time all the strains have been subcultured once every month, a total of about thirty transfers in the absence of drug.

Aminopterin. None of the strains of staphylococci was inhibited in medium B by aminopterin, even at the highest concentration tested $(0.1 \mathrm{~mm})$. Aminopterin was still inactive in the presence of just sub-inhibitory concentrations of sulphathiazole.

\section{Table 1. Sensitivity of the various strains of staphylococci to sulphonamides}

Organisms were grown in medium $B$ at $37^{\circ}$ in a set of tubes containing a serial $1 / 2$ dilution of each drug, under the semi-aerobic conditions described in Methods. Values in brackets are times of incubation (hr) before growth occurred in the highest tolerated concentration of sulphonamide.

Highest concn (M) of drug permitting growth

\begin{tabular}{|c|c|c|c|c|}
\hline Organism & Sulphathiazole & Sulphapyridine & Sulphadiazine & Sulphanilamide \\
\hline $\begin{aligned} & \text { Staphylococcus lactis } 2102 \\
& 2102 \mathrm{R} \\
& 2102 \mathrm{R} 2\end{aligned}$ & $\begin{array}{l}10^{-5}(90) \\
5 \times 10^{-4}(60) \\
5 \times 10^{-4}(50)\end{array}$ & $\begin{array}{r}* 10^{-4}(90) \\
* 2 \times 10^{-4}(20)\end{array}$ & $\begin{array}{r}* 10^{-4}(90) \\
* 2 \times 10^{-4}(20)\end{array}$ & $\begin{array}{r}5 \times 10^{-4}(90) \\
\quad * 10^{-3}(20)\end{array}$ \\
\hline $\begin{array}{l}S . \text { aureus JHM } \\
\text { JHMR }\end{array}$ & $\begin{array}{r}5 \times 10^{-6}(80) \\
\quad * 10^{-4}(60)\end{array}$ & $\begin{array}{r}* 10^{-4}(80) \\
* 2 \times 10^{-4}(40)\end{array}$ & $\begin{array}{r}2 \times 10^{-5}(80) \\
* 2 \times 10^{-4}(40)\end{array}$ & $\begin{array}{r}2 \times 10^{-4}(80) \\
* 10^{-8}(40)\end{array}$ \\
\hline $\begin{array}{l}\text { S. aureus } \mathrm{H} \\
\mathrm{HR} 2\end{array}$ & $\begin{array}{r}10^{-5}(80) \\
* 10^{-3}(60)\end{array}$ & $\begin{array}{r}10^{-4}(70) \\
* 2 \times 10^{-4}(30)\end{array}$ & $\begin{array}{r}5 \times 10^{-5}(80) \\
* 2 \times 10^{-4}(30)\end{array}$ & $\begin{array}{r}* 4 \times 10^{-4}(70) \\
* 10^{-3}(30)\end{array}$ \\
\hline S. aureus $\mathrm{R} 122$ & $5 \times 10^{-4}(40)$ & $* 2 \times 10^{-4}(30)$ & ${ }^{*} 2 \times 10^{-4}(30)$ & ${ }^{*} 10^{-3}(30)$ \\
\hline
\end{tabular}

Table 2. Sensitivity of the various strains of staphylococci to p-nitrobenzoic acid

Organisms were grown in medium $B$ at $37^{\circ}$ in a set of tubes containing a serial $1 / 2$ dilution of $p$-nitrobenzoic acid, under the semi-aerobic conditions described in Methods.

\begin{tabular}{|c|c|c|c|c|c|}
\hline \multirow[b]{2}{*}{ Organism } & \multicolumn{5}{|c|}{$\begin{array}{l}\text { Highest conen }(M) \text { of } p \text {-nitrobenzoic acid } \\
\text { permitting growth after: }\end{array}$} \\
\hline & $20 \mathrm{hr}$ & $30 \mathrm{hr}$ & $40 \mathrm{hr}$ & $50 \mathrm{hr}$ & $80 \mathrm{hr}$ \\
\hline $\begin{aligned} & \text { Staphylococcus lactis } 2102 \\
& 2102 \mathrm{R} \\
& 2102 \mathrm{R2}\end{aligned}$ & $\begin{array}{r}10^{-4} \\
10^{-4} \\
3 \times 10^{-5}\end{array}$ & $\begin{array}{r}3 \times 10^{-4} \\
10^{-3} \\
8 \times 10^{-5}\end{array}$ & $\begin{array}{l}10^{-3} \\
10^{-3} \\
10^{-8}\end{array}$ & - & - \\
\hline $\begin{array}{l}\text { S. aureus } \underset{\text { JHM }}{\text { JHMR }} \\
.\end{array}$ & $\begin{array}{l}10^{-6} \\
10^{-6}\end{array}$ & $\begin{array}{l}10^{-4} \\
10^{-4}\end{array}$ & $\begin{array}{l}10^{-4} \\
10^{-8}\end{array}$ & $\begin{array}{l}10^{-3} \\
10^{-3}\end{array}$ & - \\
\hline $\begin{array}{l}\text { S. aureus } \mathrm{H} \\
\mathbf{H R 2}\end{array}$ & $\begin{array}{l}10^{-4} \\
10^{-4}\end{array}$ & $\begin{array}{l}10^{-3} \\
10^{-3}\end{array}$ & $2 \times 10^{-3}$ & $\begin{array}{l}2 \times 10^{-3} \\
2 \times 10^{-3}\end{array}$ & - \\
\hline S. aureus $\mathrm{R} 122$ & $2.5 \times 10^{-4}$ & $<2.5 \times 10^{-4}$ & $<2.5 \times 10$ & $2.5 \times 10^{-4}$ & $10^{-3}$ \\
\hline
\end{tabular}

$p$-Nitrobenzoic acid. $p$-Nitrobenzoic acid is an analogue of $p$-aminobenzoic acid which is inhibitory to some organisms especially in the presence of aspartic acid (Davis, 1951). In medium $B$ (which contains aspartic acid) none of the strains of staphylococci was very sensitive to inhibition by $p$-nitrobenzoic acid (Table 2). Development of sulphonamide-resistance did not lead to any marked change in sensitivity to $p$-nitrobenzoic acid; Staphylococcus aureus $\mathrm{R} 122$ (the sulphonamideresistant wild strain) was the most sensitive. Inhibition by $p$-nitrobenzoic acid (mM) was prevented by $p$-aminobenzoic acid, though the final amount of growth was 
lower than in the absence of the inhibitor. There was no improvement of growth by addition of $p$-hydrozybenzoic acid, alone or together with $p$-aminobenzoic acid.

The inhibition index (Shive, 1950) is a useful concept in considering competitive inhibitions by analogues of metabolites. The value of $K$, the inhibition index, is given by $\mathbf{K}=[\mathbf{I}] /[\mathrm{S}]$, where $[\mathrm{S}]$ is the metabolite concentration and $[\mathrm{I}]$ is the inhibitor concentration which gives a defined inhibition within a constant period of time. The concentrations [I] and [S] must be great enough not to be appreciably altered during the period of the experiment by the metabolic activities of the biological system. The inhibition by sulphathiazole of the growth of staphylococci in medium $\mathrm{B}$ was completely annulled by the addition of $p$-aminobenzoate. The inhibition indices were calculated from the concentration of $p$-aminobenzoate needed to permit half-maximal growth in medium $B$ containing 2 mM-sulphathiazole after $40-45 \mathrm{hr}$ incubation (Table 3). The inhibition indices of the various strains were roughly proportional to their degreees of resistance. As the time of incubation increased so the concentration of $p$-aminobenzoic acid needed to overcome inhibition decreased. Growth in these lower concentrations of $p$-aminobenzoate was as heavy as when sulphathiazole was absent, though there was a longer lag before growth began. With higher concentrations of $p$-aminobenzoic acid growth in the presence of sulphathiazole was as rapid as in the absence of the drug.

Table 3. Relation between inhibition index and resistance of strains of staphylococci to sulphathiazole

\begin{abstract}
Organisms were grown at $37^{\circ}$ under the semi-aerobic conditions described in Methods, in medium $B$ containing $2 \mathrm{~mm}$-sulphathiazole, together with serial $1 / 2$ dilutions of $p$-aminobenzoic acid. The lowest concentration of $p$-aminobenzoate was determined that allowed at least half-maximal growth in $40-45 \mathrm{hr}$.
\end{abstract}

\begin{tabular}{|c|c|c|c|}
\hline Organism & $\begin{array}{l}\text { Inhibition } \\
\text { index }(\mathrm{K}) \\
\text { after } 40 \mathrm{hr}\end{array}$ & $\begin{array}{l}\Delta K \text { in } \\
\text { resistant } \\
\text { strain }\end{array}$ & $\begin{array}{l}\text { Degree of } \\
\text { resistance* }\end{array}$ \\
\hline $\begin{aligned} \text { Staphylococcus lactis } & 2102 \\
& 2102 \mathrm{R} \\
& 2102 \mathrm{R} 2\end{aligned}$ & $\begin{array}{r}20 \\
200 \\
200\end{array}$ & $\begin{array}{l}- \\
\times 10 \\
\times 10\end{array}$ & $\begin{array}{l}- \\
\times 25 \\
\times 25\end{array}$ \\
\hline $\begin{array}{l}\text { S. aureus JHM } \\
\text { JHMR }\end{array}$ & $\begin{array}{r}15 \\
330\end{array}$ & $\overline{\times 20}$ & $\overline{\times 20}$ \\
\hline $\begin{array}{l}\text { S. aureus } \mathrm{H} \\
\text { HR } 2\end{array}$ & $\begin{array}{r}10 \\
1000\end{array}$ & $\overline{\times 100}$ & $\overline{\times 100}$ \\
\hline S. aureus $\mathrm{R} 122$ & 660 & $\times 66 \dagger$ & $\times 100 \dagger$ \\
\hline
\end{tabular}

* In medium B without $p$-aminobenzoic acid. † Compared to $S$. aureus $\mathrm{H}$.

\title{
Metabolism of sulphathiazole
}

Cultures of the sensitive and resistant strains of staphylococci were grown from large inocula in medium $B(25 \mathrm{ml}$.) in the presence of sulphathiazole $(50 \mu \mathrm{M})$. After incubation (14 hr) the organisms were centrifuged down and the supernatant liquid heated in boiling water for $5 \mathrm{~min}$. Sulphathiazole was estimated at the beginning and at the end of the incubation by the method of Bratton \& Marshall (1939). These experiments showed no disappearance of sulphathiazole during growth.

Supernatant liquid from cultures grown in the presence of sulphathiazole (mM) 


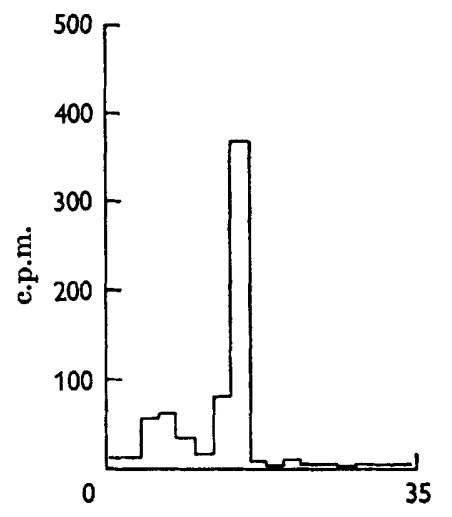

Distance from origin (cm.)

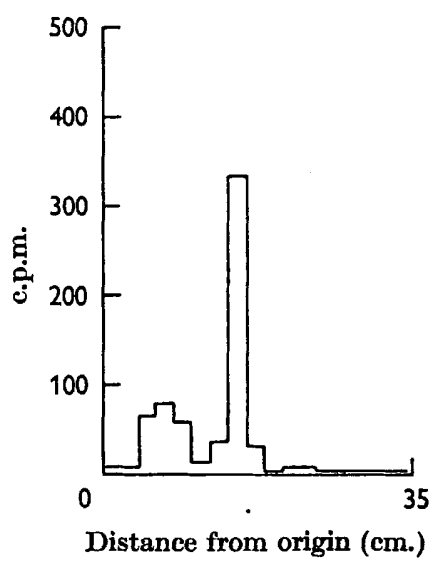

(b)

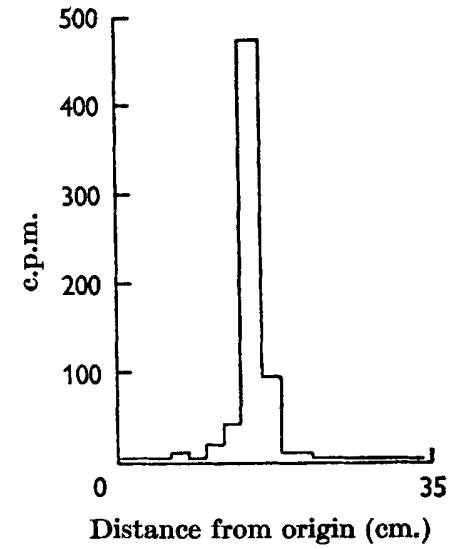

(c)

Fig. 1. Radioactivity on chromatograms of culture filtrates of Staphylococcus aureus $\mathrm{H}$ and $\mathrm{HR} 2$ grown in medium $B$ for $14 \mathrm{hr}$ in the presence of $\left.{ }^{35} \mathrm{~S}\right]$-sulphathiazole (mM). Solvent: methanol + amyl alcohol + benzene + water + ammonia. (a) $S$. aureus $\mathrm{H}$ filtrate; (b) S. aureus $\mathrm{HR} 2$ filtrate; (c) [ $\left.{ }^{\mathrm{a}} \mathrm{S}\right]$-sulphathiazole (mM) autoclaved in medium $B$ then incubated $14 \mathrm{hr}$ at $37^{\circ}$.

Table 4. Chromatography of amino compounds related to sulphathiazole

Descending chromatograms were run on Whatman No. 1 paper for about $6 \mathrm{hr}$ at room temperature.

Substance

Sulphathiazole

$p$-Aminobenzoic acid.

4-Amino-5-imidazolecarboxamide

Sulphanilic acid

Sulphanilamide

Unknown compound
$\mathbf{R}_{\mathbf{F}}$ value in:

$\begin{array}{cccc}\text { Solvent 1 } & \text { Solvent 2 } & \text { Solvent 3 } & \text { Solvent 4 } \\ 0.43 & 0.43 & 0.55 & 0.53 \\ 0.24 & 0.23 & 0.10 & 0.10 \\ 0.30 & 0.27 & - & - \\ 0.28 & - & - & - \\ 0.49 & - & - & - \\ 0.19 & 0.22 & 0.15 & 0.13\end{array}$

Solvent 1: methanol + amyl alcohol + benzene + water + ammonia; solvent 2: methanol + amyl alcohol + benzene + hydrochloric acid; solvent 8 : butanol + water; solvent 4: butanol + ammonia +water.

were also tested for their potency in inhibiting growth of a sulphathiazole-sensitive strain (Staphylococcus aureus $\mathrm{H}$ ) in medium B. The concentration of sulphathiazole in the diluted culture filtrate was taken to be the same as that of a standard solution of sulphathiazole which inhibited growth of the test organisms for the same length of time. Results from two or three dilutions of the filtrate gave values in very close agreement for the concentration of sulphathiazole in the undiluted filtrate. With all the sensitive and resistant strains of staphylococci tested there was no change in the inhibitory effect of the sulphathiazole after organisms had grown in its presence.

Chromatograms from cultures which had grown in the presence of sulphathiazole (usually mM) showed two spots of a similar brownish-red colour when diazotized and sprayed with the Bratton \& Marshall reagent. The larger spot corresponded in position to the spot given by sulphathiazole itself (Table 4). The smaller spot was 
chromatographically distinct from 4-amino-5-imidazolecarboxamide, $p$-aminobenzoic acid, sulphanilamide and sulphanilic acid; it was not present in cultures which had grown in the absence of sulphathiazole nor in autoclaved sulphathiazolecontaining medium immediately after inoculation, or after incubation (14 hr) of uninoculated medium.

Table 5. Radioactivity of $\left[{ }^{35} S\right]$-sulphathiazole and unknown compound on chromatograms

\begin{tabular}{|c|c|c|c|c|}
\hline & $\begin{array}{l}\text { c.p.m. } \\
\text { 'Unknown' }\end{array}$ & $\begin{array}{l}\text { c.p.m. } \\
\text { Sulphathiazole }\end{array}$ & $\begin{array}{l}\text { c.p.m. } \\
\text { Total }\end{array}$ & $\begin{array}{l}\% \text { of total } \\
\text { activity } \\
\text { due to } \\
\text { unknown }\end{array}$ \\
\hline Staphylococcus lactis $\underset{2102}{2102 \mathrm{R}}$ & $\begin{array}{l}22 \\
14\end{array}$ & $\begin{array}{l}265 \\
313\end{array}$ & $\begin{array}{l}\mathbf{2 9 4} \\
\mathbf{3 3 3}\end{array}$ & $\begin{array}{l}7 \\
4\end{array}$ \\
\hline $\begin{array}{r}\text { S. aureus JHM } \\
\text { JHMR }\end{array}$ & $\begin{array}{l}82 \\
73\end{array}$ & $\begin{array}{l}423 \\
436\end{array}$ & $\begin{array}{l}512 \\
517\end{array}$ & $\begin{array}{l}16 \\
14\end{array}$ \\
\hline $\begin{array}{r}\text { S. aureus } \mathrm{\text {н }} \\
\text { HR } 2\end{array}$ & $\begin{array}{l}155 \\
204\end{array}$ & $\begin{array}{l}457 \\
404\end{array}$ & $\begin{array}{l}687 \\
666\end{array}$ & $\begin{array}{l}23 \\
31\end{array}$ \\
\hline $\begin{array}{l}\text { S. aureus R } 122 \\
\text { *Sulphathiazole }\end{array}$ & $\begin{array}{l}95 \\
21\end{array}$ & $\begin{array}{l}181 \\
611\end{array}$ & $\begin{array}{l}289 \\
699\end{array}$ & $\begin{array}{r}33 \\
\mathbf{3}\end{array}$ \\
\hline
\end{tabular}

* Incubated in uninoculated medium B at $37^{\circ}(14 \mathrm{hr})$.

When liquid from cultures grown in the presence of $\left.{ }^{35 \mathrm{~S}}\right]$-sulphathiazole $(\mathrm{mm})$ were chromatographed, radioactivity was found in the same positions as the two spots revealed by the Bratton \& Marshall reagent, and nowhere else (Fig. 1). Only one peak of radioactivity was found after [ $\left.{ }^{35} \mathrm{~S}\right]$-sulphathiazole was autoclaved and incubated in uninoculated medium. An approximate estimate of the proportion of the sulphathiazole that was converted to the unknown compound by the various strains during growth was made by comparing the number of counts found in each of the two peaks (Table 5). Staphylococcus lactis 2102 and $2102 \mathrm{R}$ formed much less of the unknown material than did the strains of $S$. aureus, but there was no correlation between the activity found in the peak due to the unknown compound and the sensitivity of the strain to sulphathiazole. For this reason, the chemical nature of the unknown compound was not investigated further.

\section{Uptake of sulphathiazole by washed suspensions of staphylococci}

The amount of sulphathiazole taken up by organisms during growth in medium B was so small as to be barely detectable even when $\left[{ }^{35} \mathrm{~S}\right]$-sulphathiazole was used. The uptake was brought to a measurable value by using washed suspensions to increase the concentration of organisms. Suspensions were incubated in medium B for $1 \mathrm{hr}$ usually in the presence of $\left.{ }^{35} \mathrm{~S}\right]$-sulphathiazole $(5 \mathrm{mM})$ and the uptake of drug determined as described in Methods. Chromatography of material extracted by boiling water from Staphylococcus aureus $\mathrm{HR} 2$ after incubation with sulphathiazole showed the presence of only one diazotizable amine, which was sulphathiazole itself. The uptake of sulphathiazole by all the strains, sensitive and resistant, was 
about the same (Table 6). The uptake by $S$. aureus JHM and $\mathrm{H}$ and their resistant substrains was roughly proportional to the concentration of sulphathiazole in the medium during the incubation; the ratio: $\mathrm{m} \mu$ moles sulphathiazole $/ x \mathrm{ml}$. organisms: $\mathrm{m} \mu$ moles sulphathiazole $/ x \mathrm{ml}$. medium was fairly constant at different concentrations of sulphathiazole. A value greater than unity for this ratio indicates that the concentration of drug associated with the organisms is higher than that in the medium.

The values obtained for the uptake of sulphathiazole were compared with the amount of sulphathiazole that could be recovered from the organisms by washing with water or with a solution of sulphathiazole. The organisms which had been incubated for $1 \mathrm{hr}$ with [ $\left.{ }^{35} \mathrm{~S}\right]$-sulphathiazole $(4 \mathrm{~mm})$ were washed twice, either with water $(2 \mathrm{ml}$.) or with unlabelled sulphathiazole (mM). Each washing procedure removed a similar amount of $\left.{ }^{35} \mathrm{~S}\right]$-sulphathiazole from the organisms. This amount was the same as had been calculated to be taken up by the organisms (from the dilution of the $\left.{ }^{[35} \mathrm{S}\right]$-sulphathiazole at the beginning of the experiment). These findings indicate that the sulphathiazole taken up by the organisms was not bound firmly, but exchanged very easily with the external medium.

Table 6. Uptake of sulphathiazole from medium $B$ by washed suspensions of staphylococci

Suspensions of organisms were incubated for $1 \mathrm{hr}$ at $37^{\circ}$ in medium B with [ ${ }^{35} \mathrm{~S}$ ]sulphathiazole. Uptake was assessed by measurement of the dilution of the radioactivity by the suspension of organisms (see Methods). Values are averages of duplicate determinations.

Uptake of sulphathiazole ( $\mathrm{m} \mu$ moles/mg. dry wt. bacteria) Sulphathiazole $(\mathrm{M})$ during incubation:

\begin{tabular}{crccc}
\cline { 2 - 5 } Staphylococcus strain & $5 \times 10^{-\mathrm{a}}$ & $4 \times 10^{-8}$ & $2.5 \times 10^{-8}$ & $5 \times 10^{-4}$ \\
S. lactis 2102 & $20(1.3)$ & - & - & - \\
$2102 \mathrm{R}$ & $34(1.5)$ & - & - & - \\
S. aureus JHM & $23(1.8)$ & $15(1 \cdot 6)$ & $10(1.5)$ & $3(3.0)$ \\
JHMR & $18(1.4)$ & $18(1.8)$ & $11(2.0)$ & - \\
S. aureus H & $20(1.5)$ & - & $10(1.5)$ & - \\
HR2 & $22(1.7)$ & - & $11(2.0)$ & -
\end{tabular}

Values in brackets are for the ratio $\mathrm{m} \mu$ moles sulphathiazole $/ x \mathrm{ml}$. organisms: $\mathrm{m} \mu$ moles sulphathiazole/ $x$ ml. medium.

\section{Uptake of sulphathiazole in the presence of p-aminobenzoic acid}

Suspensions were incubated as before in medium B for an hour at $37^{\circ}$ with [ $\left.{ }^{35} \mathrm{~S}\right]$-sulphathiazole $(2.5 \mathrm{~mm})$ and various concentrations of $p$-aminobenzoic acid. The uptake of $\left[{ }^{35} \mathrm{~S}\right]$-sulphathiazole by the organisms was calculated from measurements of the radioactivity of the supernatant liquid. No difference was found in the uptake of sulphathiazole whether or not $p$-aminobenzoic acid were present ('Table 7).

\section{Growth in medium $B$}

More complex media such as tryptic meat broth or peptone water did not give much heavier or more rapid growth of the staphylococci than was found in medium B. In all the media tested, Staphylococcus lactis 2102 and its substrains grew less well than any of the strains of $S$. aureus. 


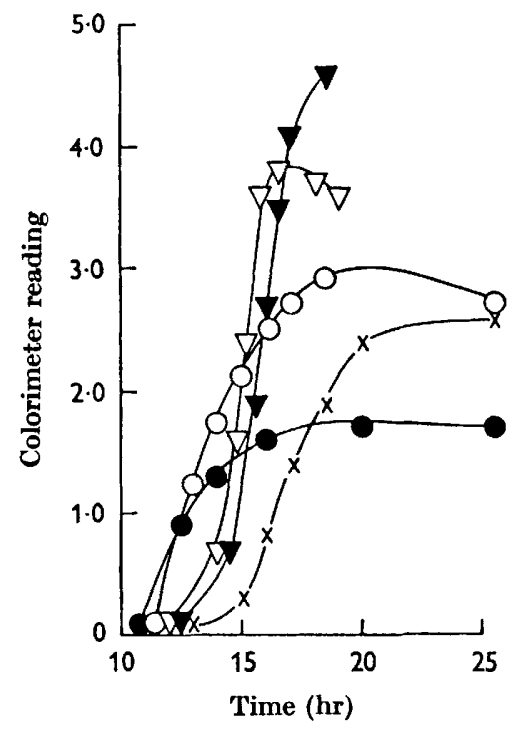

Fig. 2

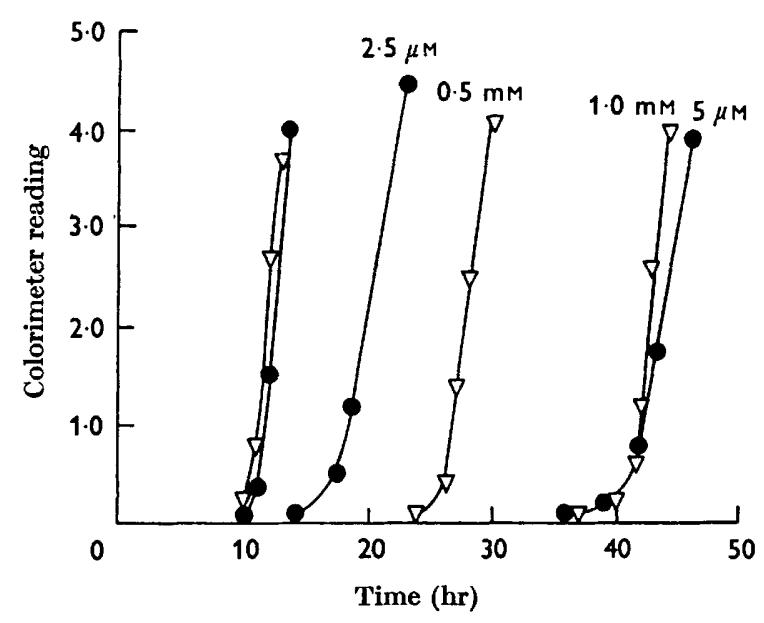

Fig. 3

Fig. 2. Aerobic growth of Staphylococcus aureus JHM and JHMR and of S. lactis 2102, $2102 \mathrm{R}$ and $2102 \mathrm{R} 2$ in medium $\mathrm{B}$ at $37^{\circ} . \nabla S$. aureus $\mathrm{JHM}, \nabla S$. aureus $\mathrm{JHMR}, O S$. lactis 2102, $S$. lactis $2102 \mathrm{R}, \times S$. lactis $2102 \mathrm{R} 2$.

Fig. 3. Aerobic growth of Staphylococcus aureus $\mathrm{B}$ and $\mathrm{HR} 2$ in medium $\mathrm{B}$ at $37^{\circ}$ in the absence and presence of sulphathiazole (at the indicated concentrations). S. aureus $\mathrm{H}$ $\nabla S$. aureus HR2.

Table 7. Uptake of $\left[{ }^{35} S\right]$-sulphathiazole by staphylococci in the presence of p-aminobenzoic acid

Suspensions of organisms were incubated $1 \mathrm{hr}$ at $37^{\circ}$ in medium B containing [ $\left.{ }^{35} \mathrm{~S}\right]-$ sulphathiazole (2.5 mM). Uptake was assessed by measurement of the dilution of the radioactivity by the suspension of organisms (see Methods). Values are averages of duplicate determinations.

\section{Staphylococcus strain}

S. aureus JHм

S. aureus JHMR

S. aureus $\mathrm{H}$

S. aureus HR 2

Concn of
$p$-aminobenzoic
acid (M)
during incubation

$$
\begin{gathered}
0 \\
2.5 \times 10^{-5} \\
2.5 \times 10^{-4} \\
2.5 \times 10^{-3} \\
0 \\
2.5 \times 10^{-6} \\
2.5 \times 10^{-5} \\
2.5 \times 10^{-4}
\end{gathered}
$$$$
0
$$$$
2 \cdot 5 \times 10^{-4}
$$$$
2.5 \times 10^{-3}
$$$$
0
$$$$
2.5 \times 10^{-5}
$$$$
2.5 \times 10^{-4}
$$$$
2.5 \times 10^{-3}
$$

$$
\mathrm{m} \mu \text { moles }
$$$$
\text { sulphathiazole }
$$$$
\text { taken up/mg. }
$$
dry wt. bacteria

$$
10
$$

12

11

12

11

11

10

9

10

11

13

11

14

14

12 


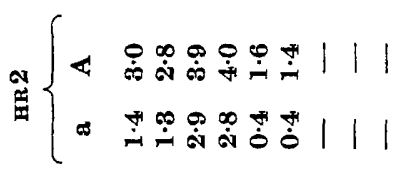

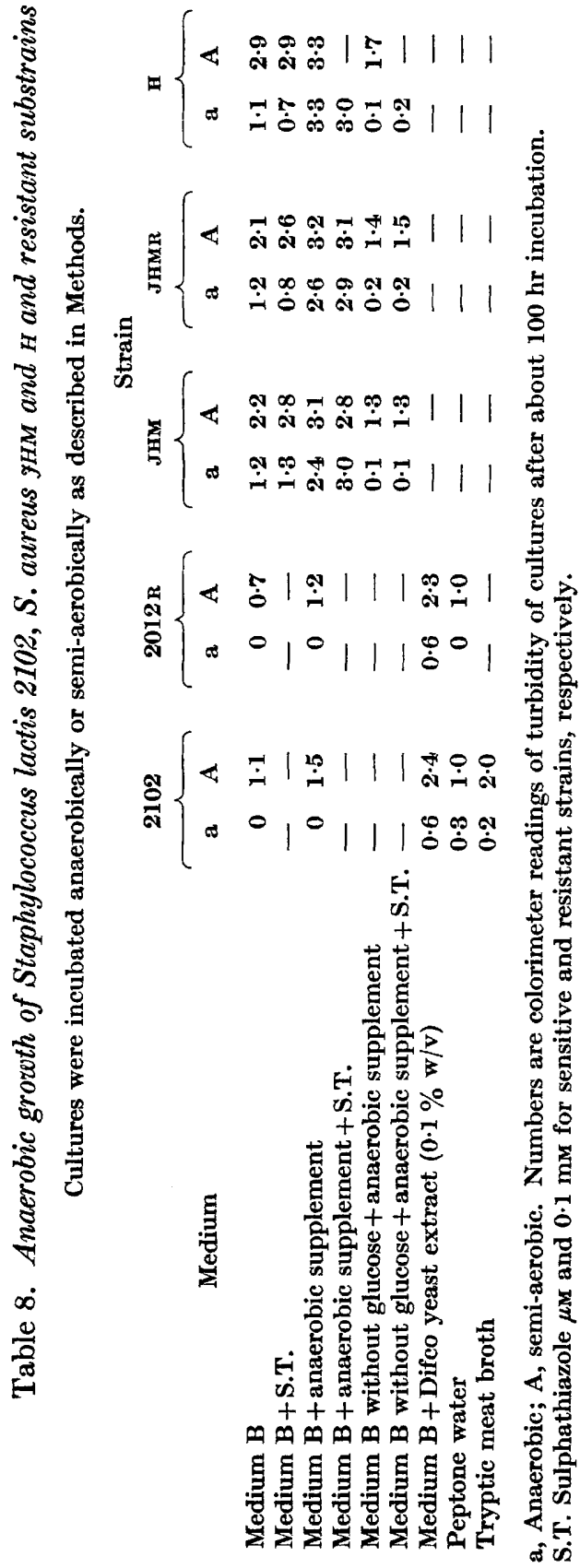


Aerobic growth. Growth curves for the various strains were measured in medium B, by using rocked $\perp$-tubes. All strains of Staphylococcus aureus, whether resistant or not, grew at about the same rate and to about the same degree in the absence of sulphathiazole. Typical growth curves, for $S$. aureus JHM and JHMR are shown in Fig. 2. S. lactis 2102 and its resistant substrains grew to a lower final value; $S$. lactis $2102 \mathrm{R} 2$ consistently showed a lag before visible growth began, about $4 \mathrm{hr}$ longer than the lag of the parent or the other resistant strain (Fig. 2).

When increasing concentrations of sulphathiazole were added to the medium, the lag phase was progressively lengthened. The final amount of growth was little affected by sulphathiazole with strains of Staphylococcus aureus; higher concentrations of sulphathiazole were required to prolong the lag phase with the resistant substrains than with the parent strains (Fig. 3).

Semi-aerobic growth. In medium B the lag phase before visible growth began was rather longer, about $15 \mathrm{hr}$, than under aerobic conditions, and maximum turbidity was not reached until about $30 \mathrm{hr}$. The highest amount of growth of strains of Staphylococcus aureus gave a colorimeter reading of $2 \cdot 0-3 \cdot 0$, and $1 \cdot 5-2 \cdot 0$ for $S$. lactis and its substrains.

Anaerobic growth. Staphylococcus aureus is a facultative anaerobe. A defined medium which supported the aerobic growth of $S$. aureus did not do so under anaerobic conditions unless carbon dioxide, pyruvate and uracil were present (Fildes \& Richardson, 1937); the presence of nitrate was also advantageous. $S$. lactis 2102 and $2102 \mathrm{R}$ grew very poorly anaerobically in several media (Table 8 ), only in medium B supplemented with yeast extract was there appreciable growth. Lascelles (1956) described a strain of $S$. aureus which grew anaerobically in the presence of haematin. However, addition of haematin to medium B did not permit anaerobic growth of $S$. lactis 2102 , indeed semi-aerobic growth was inhibited.

An absolute requirement for the supplement of uracil, pyruvate bicarbonate and nitrate was not found in Staphylococcus aureus JHM and $\mathrm{H}$ or their resistant substrains grown anaerobically in medium B, though addition of these compounds improved growth (Table 8). In the absence of glucose, however, anaerobic growth was very poor. Both sensitive and resistant strains were able to grow anaerobically in medium $\mathrm{B}$ in the presence of sulphathiazole ( $\mu \mathrm{M}$ and $0.1 \mathrm{~mm}$, respectively).

\section{Nutrition}

Amino acid requirements. Each amino acid was omitted in turn from a complete mixture which supported growth. The amino acids that were most often needed for growth were valine and arginine, which were required by all the strains of staphylococcus (Table 9). It was surprising that all strains were able to dispense with cystine and use sodium thioglycollate as main source of sulphur, since Gladstone (1937) reported that the requirement of staphylococci for cystine was the most difficult to abolish by 'training'. No changes in requirements for amino acids accompanied resistance to sulphathiazole in strains of Staphylococcus aureus, although there were differences in the requirements of the various parent strains. S. lactis 2102 grew only after $30 \mathrm{hr}$ when aspartic acid was omitted and after $60 \mathrm{hr}$ in the absence of glutamic acid. The growth of $S$. lactis $2102 \mathrm{R}$ was as rapid in the absence of either acid as it was in the complete medium $(25 \mathrm{hr})$. When both amino acids were omitted at the same time, $S$. lactis 2102 did not grow after 6 days whereas $2102 \mathrm{R}$ grew after 
2 days. Staphylococcus lactis $2102 \mathrm{R} 2$ grew in the absence of aspartic acid as rapidly as in the complete medium, but glutamic acid was absolutely required for growth within 4 days.

Vitamin requirements. Each vitamin (nicotinic acid, thiamine, biotin) was omitted in turn from medium B. All the strains of Staphylococcus aureus required for growth nicotinic acid and thiamine, but not biotin; whereas S. lactis 2102 and its substrains required only biotin. These requirements were unchanged in the presence of sulphathiazole.

Table 9. Amino acid requirements of Staphylococcus lactis 2102, S. aureus ${ }_{7 H}, \mathrm{H}$ and $\mathrm{R} 122$ and sulphonamide-resistant substrains

Organisms were grown semi-aerobically at $37^{\circ}$ (see Methods) with each amino acid omitted in turn from an otherwise complete medium.

+ Amino acid required for growth; - Amino acid not required for growth; (t) growth delayed when amino acid is omitted.

Cystine (replaced by thioglycollate); hydroxyproline; isoleucine; lysine and serine were required by none of the strains.

\begin{tabular}{|c|c|c|c|c|c|c|c|c|}
\hline \multirow[b]{2}{*}{ Amino acid omitted } & \multicolumn{8}{|c|}{ Strain } \\
\hline & 2102 & $2102 \mathrm{R}$ & 2012 R2 & JHM & JHMR & $\mathbf{H}$ & HR 2 & R 122 \\
\hline Tryptophan & + & + & + & + & + & - & - & - \\
\hline Tyrosine & + & + & + & - & - & - & - & - \\
\hline Valine & + & + & + & + & + & + & + & + \\
\hline Alanine & + & + & + & - & - & - & - & - \\
\hline Threonine & + & + & + & - & - & $(+)$ & $(+)$ & - \\
\hline Leucine & + & + & + & - & - & + & + & $(+)$ \\
\hline Methionine & + & + & + & $(+)$ & $(+)$ & $(+)$ & $(+)$ & $(+)$ \\
\hline Phenylalanine & + & + & + & - & - & + & + & - \\
\hline Arginine & + & + & + & + & + & + & + & + \\
\hline Histidine & + & + & + & + & + & - & - & + \\
\hline Aspartic acid & $(+)$ & - & - & + & + & - & - & + \\
\hline Glutamic acid & $(+)$ & - & + & - & - & - & - & - \\
\hline Proline & - & - & - & + & + & + & + & - \\
\hline Glycine & - & - & - & $(+)$ & $(t)$ & - & - & $(+)$ \\
\hline
\end{tabular}

Biochemical tests. The strains were examined by various biochemical tests used routinely in bacteriology: sugar fermentation, formation of indole, VogesProskauer, methyl red test, nitrate reduction, gelatin liquefaction and hydrogen sulphide formation. No changes accompanying resistance were found though the different parent strains showed some variations in their properties. All strains except Staphylococcus lactis 2102 and its substrains were coagulase positive, and grew on solid medium containing $7.5 \%(w / v)$ sodium chloride.

\section{DISCUSSION}

Few differences other than their sensitivities to sulphonamides were found in the present work between resistant and sensitive strains of Staphylococcus. All the strains took up similar amounts of sulphathiazole from the growth medium. Whether this uptake was at a particular site in the organisms was not established, but since the presence of $p$-aminobenzoic acid had no effect on the uptake it is unlikely that much of the sulphathiazole was combining at a site where $p$-aminobenzoate also reacted. Noll, Bang, Sorkin \& Erlenmeyer (1951) found that the uptake 
of sulphathiazole by Escherichia coli was decreased by the presence of $p$-aminobenzoic acid in the medium. There was, however, a limit below which the uptake of sulphathiazole could not be decreased by high concentrations of $\boldsymbol{p}$-aminobenzoate, therefore it was concluded that part of the sulphathiazole was free in the organism and that part was in competition with $p$-aminobenzoic acid for a receptor site. In the present work the method of measuring uptake of drug was not sufficiently refined for changes to be detected in the uptake by different parts of the organism. If much of the sulphathiazole associated with the organism were, for instance, absorbed at the cell wall, this would mask differences in the uptake of sensitive and resistant strains at other regions in the cytoplasm.

Other workers have reported that sulphonamide-resistant organisms do not take up smaller amounts of sulphathiazole than sensitive strains (Yegian \& Budd, 1945). Wacker, Trebst \& Simon (1957) found that a resistant strain of Enterococcus stei took up more sulphanilamide than did a sensitive strain, although the binding of the drug was less firm in the resistant strain. In the present work, sulphathiazole was not bound firmly by any of the strains and was easily removed by washing with water.

No evidence was found to support the view that the resistance of any strain to sulphathiazole was due to the conversion of sulphathiazole into non-inhibitory products. Sulphathiazole was partly converted to an unknown compound by growing staphylococci, but this took place in sensitive and resistant pairs of strains to similar extents. Also the proportion of sulphathiazole converted to unknown material was too small to explain the degree of resistance found in the sulphathiazole-resistant strains. Clear evidence was not obtained as to whether the unknown material was inhibitory after separation from sulphathiazole on chromatograms, perhaps because of contamination of the unknown with $p$-aminobenzoic acid, from which it was difficult to get good separation. Since culture filtrates showed the full inhibitory effect of the sulphathiazole added before incubation, it seems likely that the unknown material had inhibitory activity similar to that of sulphathiazole.

The rate of growth of sulphonamide-resistant staphylococci has been reported to be lower than that of sensitive organisms (Steers \& Sevag, 1949; Beljanski, 1953). This was not found with any of the strains of Staphylococcus aureus used in the present work. S. lactis $2102 \mathrm{R} 2$ showed a lag $4 \mathrm{hr}$ longer than did S. lactis 2102 and $2102 \mathrm{R}$, though the rate of logarithmic growth of all three strains was the same. Another difference between strain $2102 \mathrm{R}$ and strain $2102 \mathrm{R} 2$ was that the former did not grow as heavily as the parent strain in the semi-defined medium $\mathbf{B}$. This difference was not shown when strain $2102 \mathrm{R}$ was first used, but developed over a period of three years with monthly subcultivation.

Although there were differences between one sensitive strain and another in the nutritional requirements for anaerobic growth, no evidence was obtained that the development of resistance or the presence of sulphathiazole affect anaerobicmetabolism. Sevag \& Steers (1949) found that a sulphonamide-resistant strain of Staphylococcus aureus was unable to grow anaerobically, whereas the parent strain could grow to a limited extent. Steers \& Sevag (1949) also reported that two sulphonamide-resistant strains of $S$. aureus suffered a partial loss of ability to synthesize amino acids in comparison with the sensitive parent strains. In the present work 
almost no differences were found between the amino acid requirements of sensitive and resistant strains of $S$. aureus. $S$. lactis 2102 grew only after a lag when aspartic or glutamic acid was omitted from the medium, whereas strain $2102 \mathrm{R}$ grew normally in the absence of either acid, though not of both together. The greater ability of the resistant strain to synthesize glutamic acid might be related to the increase in the synthesis of folic acid, which contains glutamic acid in its molecule. Lam \& Sevag (1957) gave some evidence that sulphathiazole inhibited transaminase activity in a sensitive strain of $S$. aureus. It may be that in strain $2102 \mathrm{R}$, transaminase activity has increased with the development of resistance, resulting in an increased rate of synthesis of aspartic and glutamic acid from oxaloacetic and $\alpha$-oxoglutaric acids, respectively. These interpretations, however, are not valid for $S$. lactis $2102 \mathrm{R} 2$ which has an absolute requirement for glutamic acid but is able to grow without added aspartic acid.

Two possible mechanisms of resistance that have not been explored are the presence in the resistant strains of an increased amount of a $p$-aminobenzoateutilizing enzyme or a changed relative affinity of an enzyme for $p$-aminobenzoic acid and sulphathiazole in the resistant strains. If an increased number of receptor sites for $p$-aminobenzoate were present in a resistant strain, then all analogues of $p$-aminobenzoic acid should become less effective inhibitors, and cross-resistance to $p$-nitrobenzoic acid would be expected. In fact, no appreciable cross-resistance to $p$-nitrobenzoic acid was observed in any of the sulphonamide-resistant strains.

The second possibility, a change in the relative affinities of an enzyme for $p$-aminobenzoic acid and sulphonamides, is compatible with all the experimental observations. It accounts for the increase in the inhibition index in the resistant strains and for the decreased sensitivity of the synthesis of folic acid (White \& Woods, 1965) in these strains to inhibition by sulphathiazole. A decreased affinity for sulphonamides might well be specific (Davis \& Maas, 1952) and the affinity for other inhibitors of $p$-aminobenzoate utilization, such as $p$-nitrobenzoic acid, might be unchanged. The evidence for this mechanism of resistance is indirect, but its value is strengthened by the evidence that other mechanisms are not operating.

One of us (P.J.W.) is indebted to the Medical Research Council for a training scholarship held during the period of this work. We wish to thank May \& Baker Ltd, Dagenham, Essex for generous information about the preparation of sulphathiazole, and for a gift of specially purified 2-aminothiazole.

\section{REFERENCES}

BeluANSki, M. (1953). Comparaison de souches bactériennes résistantes à des antibiotiques avec des souches sensibles de même espèce III. Cas du sulphamide. Ann. Inst. Pasteur, 84, 756.

Bratton, A. C. \& Marshall, E. K. JR (1939). A new coupling component for sulphanilamide determination. J. biol. Chem. 128, 537.

Conway, E. J. \& Downey, M. (1950). An outer metabolic region of the yeast cell. Biochem. $J, 47,347$.

Davrs, B. D. (1951). Inhibition of Escherichia coli by $p$-nitrobenzoic acid and its reversal by $p$-hydroxybenzoic acid. J. exp. Med. 94, 243.

Davis, B. D. (1957). Physiological (phenotypic) mechanisms responsible for drug resistance. In Drug Resistance in Micro-organisms. Ed. by G. E. W. Wolstenholme and C. M. O'Connor, p. 165. London: J. and A. Churchill, Ltd. 
Davis, B. D. \& MaAs, W. K. (1952). Analysis of the biochemical mechanism of drug resistance in certain bacterial mutants. Proc. natn. Acad. Sci., U.S.A. 38, 775.

Ekman, B. (1948). Paper chromatography of primary aromatic amines. Acta chem. scand. $2,383$.

Fildes, P. \& Richardson, G. M. (1937). The nutrition of Staphylococcus aureus: sulphur requirements. Br. J. exp. Path. 18, 292.

Fosbinder, R. J. \& Walter, L. A. (1939). Sulphanilamido derivatives of heterocyclic amines. J. Amer. chem. Soc. 61, 2032.

Francis, G. E., Mulligan, W. \& Wormald, A. (1954). Isotopic Tracers. London: The Athlone Press.

Gilman, H. (1932). p-Acetaminobenzenesulphonyl chloride. Org. Synth. Col. 1, 8.

Gradstone, G. P. (1937). The nutrition of Staphylococcus aureus; nitrogen requirements. Br. J. exp. Path. 18, 322.

Kolmer, J. A. \& Boerner, F. (1945). Approved Laboratory Technic, 4th edition. New York: D. Appleton-Century Co. Inc.

LAM, G. T. \& Sevag, M. G. (1957). Drug-induced depression of transaminases of drugsensitive Staphylococcus aureus. Bact. Proc. p. 35.

Lascelues, J. (1956). An assay of iron protoporphyrin based on the reduction of nitrate by a variant strain of Staphylococcus aureus; synthesis of iron protoporphyrin by suspensions of Rhodopseudomonas spheroides. J. gen. Microbiol. 15, 404.

Mackie, T. J. \& McCartney, J. E. (1931). An Introduction to Practical Bacteriology, 3rd Edition. Edinburgh: E. and S. Livingstone.

Mrtcheld, P. (1953). Transport of phosphate across the surface of Micrococcus pyogenes: Nature of the cell 'inorganic phosphate'. J. gen. Microbiol. 9, 273.

Morris, J. G. \& Woons, D. D. (1959). Inter-relationships of serine, glycine and vitamin $\mathrm{B}_{6}$ in the growth of mutants of Escherichia coli. J. gen. Microbiol. 20, 576.

Noll, H., Bang, J., Sorkin, E. \& Erlenmeyer, H. (1951). Über die Wirkung eines mit ${ }^{35} \mathrm{~S}$ indizierten Sulfathiazols auf Kulturen von Escherichia coli. Helv. chim. acta, 34, 340.

SevaG, M. G. \& STEErs, E. (1949). The mechanism of resistance to sulfonamides V. A quantitative study of the alternate metabolic pathways involving tryptophan and glucose metabolism, and aerobic and anaerobic growth conditions in relation to the mechanism of resistance. Archs Biochem. 24, 144.

SHIVE, W. (1950). The utilization of antimetabolites in the study of biochemical processes in living organisms. Ann. N.Y. Acad. Sci. 52, 1212.

Steers, E. \& Sevag, M. G. (1949). The mechanism of resistance to sulfonamides IV. A comparative study of the amino acid metabolism of Staphylococcus aureus in relation to the mechanism of resistance. Archs Biochem. 24, 129.

Wacker, A., Trebst, A. \& Simon, H. (1957). Über den Stoffwechsel des Sulfanilamids$\left.{ }^{[5} \mathrm{S}\right]$ bei empfindlichen und resistenten Bakterien. Z. Naturf. 12B, 315.

White, P. J. \& Woons, D. D. (1965). The synthesis of $p$-aminobenzoic acid and folic acid by staphylococci sensitive and resistant to sulphonamides. J. gen. Microbiol. 40, 243.

YEGIAN, D. \& BuDD, V. (1945). The permeability of mycobacteria to sulphonamides and sulphonamide-like agents. J. Pharmacol. 84, 318. 